\title{
SEM and EPMA Analysis of Spark Plug Electrode Erosion
}

\author{
L.R. Walker*, H.T. Lin*, I. Levina**, M.P. Brady*, J. Lykowski** \\ *Metals and Ceramics Division, Oak Ridge National Laboratory, Oak Ridge, TN 37831-6064 USA \\ ** Federal Mogul Corporation Ignition Products, 900 Upton Av. Toledo, OH 43607 USA
}

Ignition systems are one of the key technologies to achieve cost/performance/emission characteristic goals for lean and stoichiometric industrial natural gas reciprocating engines. In natural gas applications spark breakdown voltages are very high requiring small and consistent gaps for reliable ignition. As a consequence erosion and corrosion of spark plug electrode materials is a major issue as excessive electrode wear results in costly downtime for spark plug replacement. As cylinder pressures, compression ratios, and ignition voltages are increased, and conditions further move towards leaner burning combustion, spark plug reliability and lifetime performance will become even more critical and could limit further advances in engine development. The near-term goal of this work is to characterize used spark plugs after a variety of field service and/or controlled engine test conditions to gain insight into the electrode corrosion/erosion processes that limit the spark plug lifetime. The long-term goal is to design new electrode materials based on a fundamental understanding gained from this characterization work.

Fig. 1 shows an SEM cross-section of an industrial natural gas engine J-type spark plug after over $4000 \mathrm{~h}$ of field service [1]. The electrodes consisted of a Ni-base alloy (nominally 90-95 wt.\% Ni) with inserts of Pt-4W and Ir alloys at the ground and center electrodes, respectively. Significant erosion was evident, ranging from $30-40 \%$ for the Pt-W and $10-15 \%$ for the Ir insert. Substantial intergranular cracking was observed at the surfaces of both Pt-W and Ir electrode inserts (Figs. 2, 3) [1]. Additionally, an oxidized crack was found to extend along much of the interface between the $\mathrm{Ni}$ alloy and the Pt-4W insert, nearly completely separating the Pt-4W tip from the ground electrode (Fig. 4) [1]. Such cracking plus oxide formation have been consistently observed in many end-oflife used plugs, and is suspected to be the life-limiting final step in the wear/erosion process.

Figs. 5 and 6 are composite elemental maps from a cross-section of the ground electrode region of a spark plug after a severe cycle laboratory gasoline engine test. This particular plug utilized a Pt- $4 \mathrm{~W}$ insert on a Ni-base alloy electrode of nominally $75 \% \mathrm{Ni}$. Despite significantly different test/engine conditions, similar degradation to that observed in the field-tested natural gas engine plug (Figs. 14) was observed. The composite maps show cracking and oxidation at the Ni-alloy electrode/Pt- $4 \mathrm{~W}$ insert interface (Figs 5, 6). Additionally, SEM images (not shown here) indicated intergranular cracking at the surface of the Pt-4W tip, similar to that observed in Figs. 2, 3. These findings suggest that in addition to surface erosion processes during sparking resulting from physical mechanisms such as sputtering, melting, ablation, and particle erosion, oxidation-driven attack and materials compatibility between the electrode alloy and the platinum group/precious metal insert play a key role in electrode erosion and spark plug lifetime under actual operating conditions. Microstructural characterization of a range of engine-tested spark plug electrode/insert materials will be presented [2].

[1] H.T. Lin, M.P. Brady, and R.K. Richards, D.M. Layton, Wear (in press).

[2] Research at Oak Ridge National Laboratory (ORNL) was jointly sponsored by the U.S. Department of Energy, Office of Distributed Energy, Distributed Energy Materials Program and Advanced Reciprocating Engine Systems Program, under contract DE-AC05-00OR22725 with UT-Battelle, LLC. 


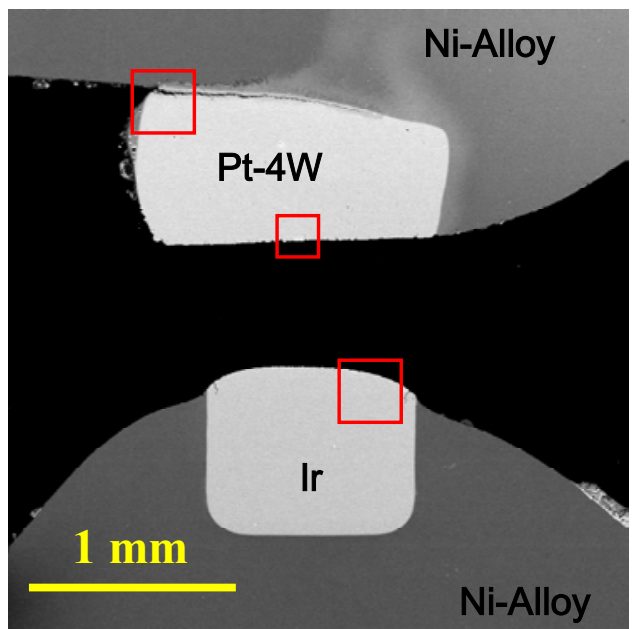

Fig.1. BSE image of Pt-4W - Ir electrodes

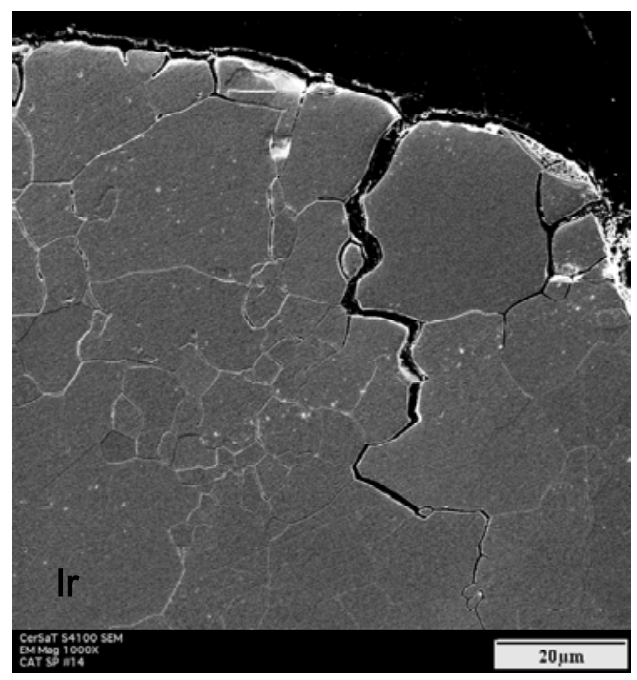

Fig.3 SE image of cracking at surface of Ir electrode.

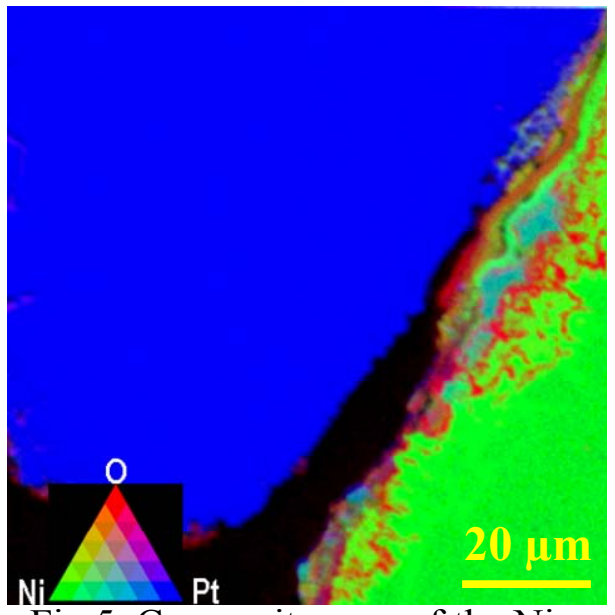

Fig.5. Composite map of the Nialloy/Pt-4W interface

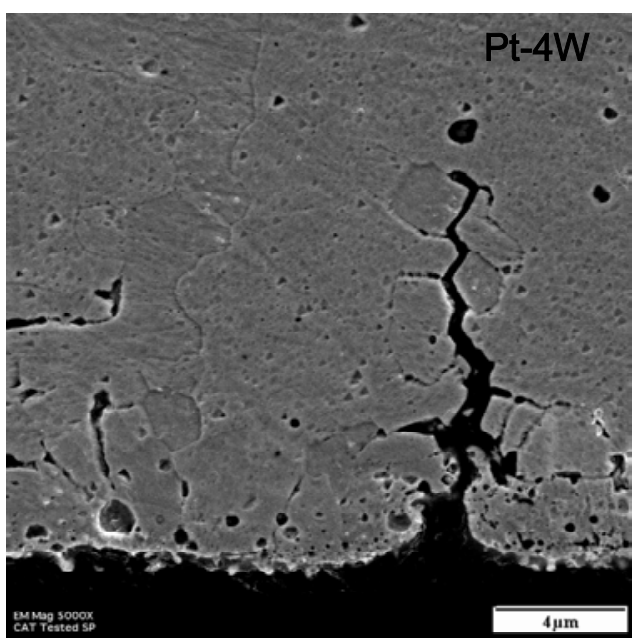

Fig.2 SE image of cracking at surface Pt-4W electrode.

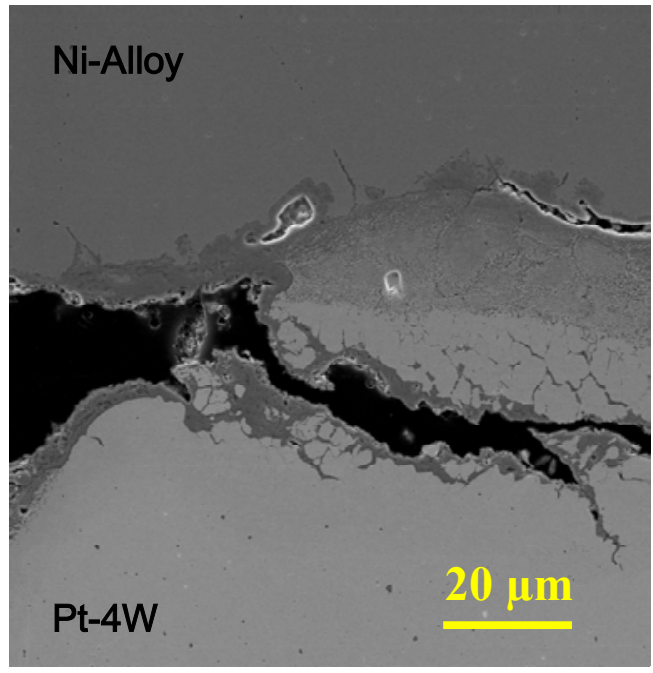

Fig.4 BSE image of cracking and oxidation at insert interface

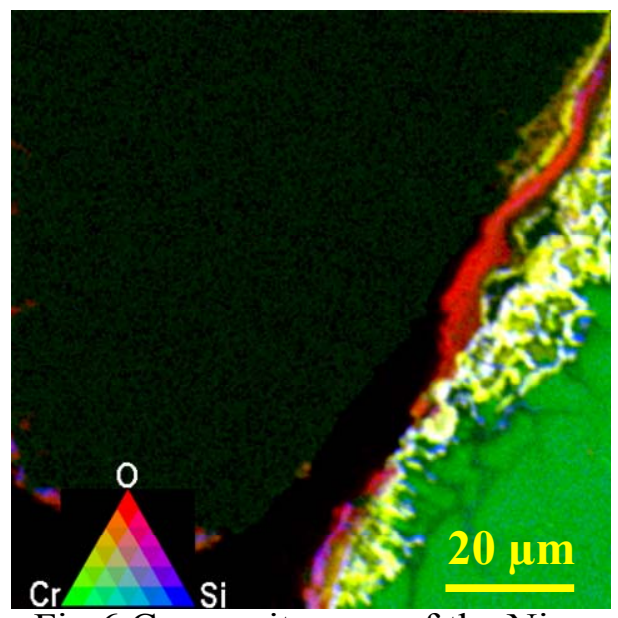

Fig.6.Composite map of the Nialloy/Pt-4W interface 